\title{
Modeling the effects of organic nitrogen uptake by plants on the carbon cycling of boreal forest and tundra ecosystems
}

\author{
Q. Zhu ${ }^{1,2}$ and Q. Zhuang ${ }^{1,2,3}$ \\ ${ }^{1}$ Purdue Climate Change Research Center, Purdue University, West Lafayette, Indiana, USA \\ ${ }^{2}$ Department of Earth, Atmospheric, and Planetary Sciences, Purdue University, West Lafayette, Indiana, USA \\ ${ }^{3}$ Department of Agronomy, Purdue University, West Lafayette, Indiana, USA
}

Correspondence to: Q. Zhu (zhuq@purdue.edu)

Received: 10 July 2013 - Published in Biogeosciences Discuss.: 13 August 2013

Revised: 5 November 2013 - Accepted: 6 November 2013 - Published: 6 December 2013

\begin{abstract}
Boreal forest and tundra are the major ecosystems in the northern high latitudes in which a large amount of carbon is stored. These ecosystems are nitrogen-limited due to slow mineralization rate of the soil organic nitrogen. Recently, abundant field studies have found that organic nitrogen is another important nitrogen supply for boreal forest and tundra ecosystems. In this study, we incorporated a mechanism that allowed boreal plants to uptake small molecular amino acids into a process-based biogeochemical model, the Terrestrial Ecosystem Model (TEM), to evaluate the impact of organic nitrogen uptake on ecosystem carbon cycling. The new version of the model was evaluated for both boreal forest and tundra sites. We found that the modeled organic nitrogen uptake accounted for 36-87\% of total nitrogen uptake by plants in tundra ecosystems and 26-50\% for boreal forests, suggesting that tundra ecosystem might have more relied on the organic form of nitrogen than boreal forests. The simulated monthly gross ecosystem production (GPP) and net ecosystem production (NEP) tended to be larger with the new version of the model since the plant uptake of organic nitrogen alleviated the soil nitrogen limitation especially during the growing season. The sensitivity study indicated that the most important factors controlling the plant uptake of organic nitrogen was the soil amino acid diffusion coefficient $\left(D_{\mathrm{e}}\right)$ in our model, suggesting that the organic nitrogen uptake by plants is likely to be regulated by the edaphic characteristics of diffusion. The model uncertainty due to uncertain parameters associated with organic nitrogen uptake of the tundra ecosystem was larger than the boreal forest ecosystems. This study suggests that considering the organic nitrogen uptake
\end{abstract}

by plants is important to carbon modeling of boreal forest and tundra ecosystems.

\section{Introduction}

Terrestrial ecosystems play an important role in cycling carbon between land and the atmosphere through photosynthesis, plant respiration and soil respiration (Heimann et al., 1998; Melillo et al., 1993). The major terrestrial ecosystem processes associated with carbon cycling are significantly constrained by the carbon $(\mathrm{C})$ and nitrogen $(\mathrm{N})$ interactions (Berendse and Aerts, 1987; Lin et al., 2000; Tateno and Chapin, 1997). In $\mathrm{N}$ infertile environments, plants have low access to $\mathrm{N}$ and there is a high $\mathrm{C} / \mathrm{N}$ ratio in the litter. The high $\mathrm{C} / \mathrm{N}$ ratio litter slows down $\mathrm{N}$ mineralization, decreasing available $\mathrm{N}$ in the soil and limiting the plants' ability to assimilate carbon. The nitrogen limitation effect on carbon cycling has also been confirmed by the elevated $\mathrm{CO}_{2}$ studies (Norby et al., 2010; Reich et al., 2006a, b). The feedback between carbon and nitrogen cycles could reduce the $\mathrm{CO}_{2}$ fertilization effect and thus strongly affect the plant carbon productivity. Therefore, the nitrogen cycling is critically important to carbon cycling, especially in regions where the $\mathrm{N}$ availability is limited (e.g., McGuire et al., 1992; Sokolov et al., 2008).

The existing terrestrial nitrogen cycling models are based on two assumptions. The first one is that plants are only able to utilize inorganic forms of nitrogen (e.g., Black, 1993). As a result, soil organic nitrogen needs to be mineralized (e.g., to $\mathrm{NH}_{4}^{+}, \mathrm{NO}_{3}^{-}$) by microbes before being taken up by plants. 
Microbial activity decomposes the organic compounds and produces ammonia or nitrate as byproducts that plants are able to assimilate (Harmsen and Van Schreven, 1955). The second one is that plants compete poorly against microbes in acquiring inorganic nitrogen; microbes decompose soil organic matter (SOM) for survival and assimilate as much inorganic nitrogen product as they can, meaning that plants can only access leftover inorganic nitrogen after microbes have met their demands. The leftover nitrogen is defined as net mineralization, which is a central component in terrestrial nitrogen cycling (Schimel and Bennett, 2004). Based on this assumption, net mineralization indicates the maximum amount of inorganic nitrogen that is ready to be used by plants or to be leached out from the ecosystem.

These two classical nitrogen cycling assumptions have been challenged for decades. The discrepancy between net mineralization nitrogen and plant uptake nitrogen has been observed over a variety of ecosystem types (e.g., Chapin et al., 1988; Dyck et al., 1987). Some studies found that organic nitrogen is also an important source of plant nitrogen (Bennett and Prescott, 2004; Schimel and Chapin, 1996) in nitrogen-limited ecosystems, such as arctic tundra (Chapin et al., 1993), boreal forest (Nasholm et al., 1998), and alpine tundra (Lipson et al., 2001; Lipson and Monson, 1998). Some other research projects, however, have explained the additional nitrogen uptake to be a result of enhanced competitive capability of plants against microbes in order to acquire inorganic nitrogen with the help of mycorrhizae (Hodge et al., 2000a, b). Although some studies argue that amino acids are actually taken up by the plant through a mycorrhizal symbiont rather than directly absorbed by plant root (e.g., Jones et al., 2005), it is accepted as fact that both mycorrhizal and non-mycorrhizal plants from various ecosystems are able to use organic forms of nitrogen (Chapin et al., 1993; Lipson and Nasholm, 2001; Nasholm et al., 1998, 2009), bypassing the classical pathway of purely using inorganic nitrogen.

The mycorrhizae have a symbiotic relationship with terrestrial plants that allows for the absorption of organic nitrogen from the soil and helps to transport this nitrogen into plant roots; in return, the mycorrhizae obtain carbon from their photo-symbiont for their own growth and respiration (Hobbie et al., 2006; Smith and Read, 1997). Mycorrhizae survive on the plant, which provides them with a relatively large amount of carbon, instead of relying on carbon from decomposing soil organic matter (SOM). As a result, mycorrhizae are relatively carbon-rich, and they potentially have more extra energy available to produce bio-expensive enzymes, which are used to break down organic nitrogen such as amino acids or even some proteins. Some studies have indicated that around half of the plant-utilized nitrogen is provided through this mycorrhizal fungi pathway in the arctic tundra (Hobbie et al., 2006; Kielland, 1994). Non-mycorrhizal plants are also capable of directly accessing the organic form of nitrogen in nitrogen poor environments (e.g., Chapin et al., 1993; Persson et al., 2003). Such organic uptake involves two impor- tant factors, one is the concentration of simple organic nitrogen compounds, usually amino acids, in the soil near the root surface, and the other is uptake kinetics. Simple organic compound could be directly used by plants, while complex organic compounds uptake requires bio-expensive enzymes such as those produced by mycorrhizal fungi. It has been estimated that nearly $60 \%$ of the nitrogen uptake by plants is from free amino acids in the arctic tundra (Chapin et al., 1993). Therefore, amino acids taken up by non-mycorrhizal plants become an important issue when modeling nitrogen cycling in arctic ecosystems (Leadley et al., 1997).

Most biogeochemical ecosystem models assume that inorganic nitrogen is the only N source for plants (e.g., McGuire et al., 1992; Parton et al., 1993; Potter et al., 1993; Raich et al., 1991; Running and Coughlan, 1988; Running and Gower 1991; Zhuang et al., 2010). However, it has been increasingly recognized by the terrestrial ecosystem research community that simple organic nitrogen compounds are potentially also an important source for plant nitrogen uptake (Bennett and Prescott, 2004; Chapin et al., 1993; Nasholm et al., 1998; Schimel and Chapin, 1996). Plants compete poorly against microbes in acquiring amino acids. However, in general, plants are still able to acquire enough amino acids because the soil amino acid production is about an order of magnitude higher than plant $\mathrm{N}$ demand (Lipson et al., 1998, 1999). A plant organic and inorganic nitrogen uptake kinetics model for arctic ecosystems was constructed to determine uptake control factors (Leadley et al., 1997). It modeled the root uptake using Michaelis-Menten uptake kinetics. In this model, the soil amino acid supply rate estimation was however still lacking. Lipson hypothesized that soil amino acid concentrations can be empirically modeled based on the soil proteolysis rate and the rate of amino acid uptake by microbes, in addition to temperature and moisture effects (Lipson et al., 2001). This empirical model quantitatively estimates the amino acid supply rate, which potentially provides an important parameter for the plant root uptake kinetics model (Leadley et al., 1997).

In this study, we coupled an organic nitrogen uptake algorithm into the existing process-based Terrestrial Ecosystem Model (TEM; Melillo et al., 1993; Raich et al., 1991; Zhuang et al., 2003) by incorporating root uptake kinetics (Leadley et al., 1997) and soil amino acids transformation (Lipson et al., 2001). We hypothesize that both organic nitrogen (amino acids) and inorganic nitrogen are important nitrogen supplies and have strong effects on terrestrial carbon cycling. The model was applied to quantify the amount of the organic nitrogen uptake for both tundra and boreal forest ecosystems. We also examined how the modeled carbon dynamics will be affected by this new nitrogen uptake algorithm in the model. The estimated carbon fluxes were compared with observations to show if the model predictability is improved by incorporating the nitrogen uptake mechanism into ecosystem carbon modeling. 


\section{Method}

\subsection{Overview}

In this study, we first coupled the mechanisms of organic nitrogen uptake algorithm into the TEM (hereafter referred to as ON-TEM). We then used an adjoint version of TEM (Zhu and Zhuang, 2013) to parameterize both original TEM and ON-TEM using AmeriFlux observation data of NEP and GPP. More details about adjoint TEM parameterization method are presented in Appendix A. Third, we compared TEM and ON-TEM simulations of ecosystem carbon and nitrogen fluxes. Fourth, since organic nitrogen uptake module parameters are directly derived from previous studies, we conducted an uncertainty analysis to examine how uncertain parameters affect simulated organic nitrogen uptake at boreal forest and tundra sites. Finally, sensitivity studies of ONTEM are conducted to evaluate the importance of several key parameters in controlling organic $\mathrm{N}$ uptake dynamics. The importance of these parameters associated with different processes of organic nitrogen uptake is ranked.

\subsection{Model development}

The Terrestrial Ecosystem Model (TEM; Melillo et al., 1993; Raich et al.1991; Zhuang et al., 2001, 2002, 2003, 2010) quantifies terrestrial carbon and nitrogen fluxes and their pool sizes across space and time, driven by spatially explicit data, which include surface characteristics (soil texture, plant functional type, elevation) and climate (precipitation, air temperature, incident radiation). Carbon (C) and nitrogen $(\mathrm{N})$ interactions were refined by incorporating a nitrogen availability (NA) scaling factor in calculating GPP and NPP (McGuire et al., 1992). It was concluded that the nitrogen limitation is weak in tropical and temperate forests, but much stronger in boreal forest and tundra ecosystems. Here we further improve the nitrogen cycling representation in TEM by coupling a mechanism wherein plants can take up amino acids in boreal forest and tundra ecosystems. The new version of TEM is formulated as follows:

$$
\begin{aligned}
& \frac{\mathrm{d} C_{\mathrm{V}}}{\mathrm{d} t}=\mathrm{GPP}-R_{\mathrm{A}}-L_{\mathrm{C}} \\
& \frac{\mathrm{d} \mathrm{C}_{\mathrm{S}}}{\mathrm{d} t}=L_{\mathrm{C}}-R_{\mathrm{H}} \frac{\mathrm{d} \mathrm{N}_{\mathrm{V}}}{\mathrm{d} t}=\text { NUPTAKE_AV }+ \text { NUPTAKE_AC }-L_{\mathrm{N}} \\
& \frac{\mathrm{d} \mathrm{N}_{\mathrm{S}}}{\mathrm{d} t}=L_{\mathrm{N}}-\text { NETMIN }- \text { PROTEOLYSIS }+ \text { NUPTAKE_MI } \\
& \frac{\mathrm{dN} \mathrm{AV}}{\mathrm{d} t}=\text { NETMIN }- \text { NUPTAKE_AV } \\
& \frac{\mathrm{dN} \mathrm{NC}_{\mathrm{AC}}}{\mathrm{d} t}=\text { PROTEOLYSIS }- \text { NUPTAKE_MI }- \text { NUPTAKE_AC }
\end{aligned}
$$

ON-TEM consists of six pools that include carbon in vegetation $\left(\mathrm{C}_{\mathrm{V}}\right)$, carbon in soil $\left(\mathrm{C}_{\mathrm{S}}\right)$, nitrogen in vegetation $\left(\mathrm{N}_{\mathrm{V}}\right)$, large organic nitrogen compounds in soil $\left(\mathrm{N}_{\mathrm{S}}\right)$, inorganic nitrogen in soil $\left(\mathrm{N}_{\mathrm{AV}}\right)$ and amino acids in soil $\left(\mathrm{N}_{\mathrm{AC}}\right)$. Ten fluxes represent the exchange of carbon and nitrogen in the system, which are gross primary production (GPP), autotrophic respiration $\left(R_{\mathrm{A}}\right)$, litter carbon production $\left(L_{\mathrm{C}}\right)$, litter nitrogen production $\left(L_{\mathrm{N}}\right)$, heterotrophic respiration $\left(R_{\mathrm{H}}\right)$, net mineralization (NETMIN), inorganic nitrogen uptake by plant (NUPTAKE_AV), the nitrogen uptake by plants from amino acids pool (NUPTAKE_AC), organic nitrogen compound proteolysis (PROTEOLYSIS) and its uptake by microbes (NUPTAKE_MI). Compared with the previous version of TEM (Zhuang et al., 2003; 2010), Eq. (6) was revised to model amino acids pool and fluxes (Fig. 1).

Following Lipson et al. (2001), the changes in the amino acid pool are modeled as the balance of three components (1) soil proteolysis, (2) microbial uptake and (3) plant uptake (Fig. 1). Soil proteolysis is estimated with an exponential function of temperature:

PROTEOLYSIS $=P \cdot e^{\frac{\ln (P Q 10)}{10} \cdot T}$,

where $P$ is the seasonal mean proteolysis rate, T is soil temperature, and $P Q 10$ is the temperature $Q 10$ parameter on proteolysis. Microbial uptake is modeled as a function of temperature and soil moisture:

$\mathrm{NUPTAKE} \_\mathrm{MI}=R \cdot \mathrm{N}_{\mathrm{AC}} \cdot e^{\frac{\ln (R Q 10)}{10} \cdot T} \cdot \mathrm{MOIST}$,

where $\mathrm{R}$ is the seasonal mean amino acid uptake rate, $\mathrm{N}_{\mathrm{AC}}$ is amino acid pool size, and RQ10 is the temperature Q10 parameter on the microbial amino acid uptake. MOIST represents the moisture effect on uptake rate, which is modeled with a third order polynomial function of soil moisture:

$$
\begin{aligned}
\text { MOIST } & =\text { AMOIST } \cdot M^{3}+\text { BMOSIT } \cdot M^{2} \\
& + \text { CMOIST } \cdot M+\text { DMOIST }
\end{aligned}
$$

where $M$ is soil moisture content. AMOIST, BMOIST, CMOIST, and DMOIST are third-order, second-order, first-order and zero-order coefficients, respectively. The AMOIST, BMOIST, CMOIST, and DMOIST define an empirical relationship between soil water content $(M)$ and its effect on microbial amino acid uptake rate. These parameter values are derived from Lipson et al. (2001).

To model the amount of amino acid taken up by plants (NUPTAKE_AC), we adopted algorithms from existing nitrogen root uptake kinetics models (Barber and Cushman, 1981; Itoh and Barber, 1983; Leadley et al., 1997). These algorithms assume that nitrogen compounds are moved towards the root surface and would be actively taken up as long as they touch the root surface (Fig. 2). The uptake mechanism is described with Michaelis-Menten kinetics. The nitrogen flow is determined by both mass flow and compound concentration gradient induced diffusion. The soil surrounding 


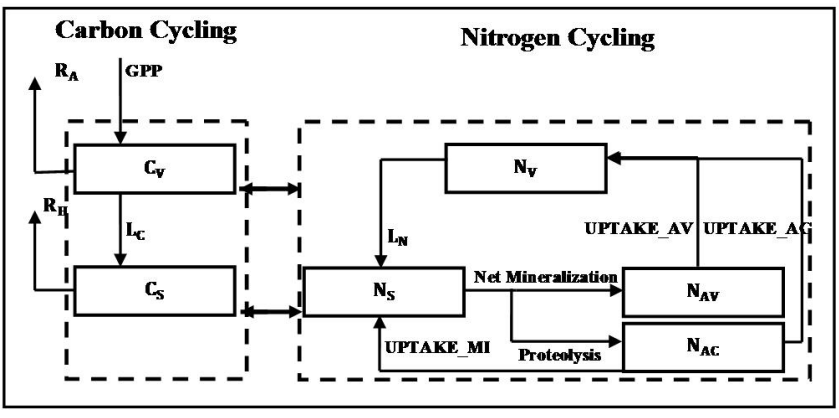

Fig. 1. ON-TEM model diagram: arrows are carbon or nitrogen fluxes; the boxes are state variables. The original TEM comprises five state variables: vegetation carbon $\left(\mathrm{C}_{\mathrm{V}}\right)$, soil organic carbon $\left(C_{S}\right)$, vegetation nitrogen $\left(N_{V}\right)$, soil organic nitrogen $\left(N_{S}\right)$ and soil inorganic nitrogen $\left(\mathrm{N}_{\mathrm{AV}}\right)$. Here an amino acid pool $\left(\mathrm{N}_{\mathrm{AC}}\right)$ is added. In ON-TEM, soil nitrogen has two pathways to be taken up by plants: (1) nitrogen is mineralized by soil microbes into inorganic form, $\mathrm{NH}_{4}^{+}, \mathrm{NO}_{3}^{-}$or (2) nitrogen undergoes proteolysis into amino acids and is taken up by the plant.

the rooting system is divided into many thin subcylinders, starting from the root surface to the outer boundary of the rhizosphere. For the $i$ th sub-cylinder, the change in the number of exchangeable amino acid molecules with time $\left(\frac{\Delta N(i)}{\Delta t}\right)$ is formulated as follows:

$$
\begin{aligned}
& \frac{\Delta N(i)}{\Delta t}=2 \pi l \Delta\left(r F_{\mathrm{d}}\right)+2 \pi l \Delta\left(r F_{\mathrm{m}}\right)+\pi l \Delta\left(r^{2}\right) S(i) \\
& \Delta\left(r F_{\mathrm{d}}\right)=r(i+1) \cdot F_{\mathrm{d}}(i+1)-r(i) \cdot F_{\mathrm{d}}(i) \\
& \Delta\left(r F_{\mathrm{m}}\right)=r(i+1) \cdot F_{\mathrm{m}}(i+1)-r(i) \cdot F_{\mathrm{m}}(i) \\
& \Delta\left(r^{2}\right)=r(i+1)^{2}-r(i)^{2},
\end{aligned}
$$

where $\Delta$ denotes change of a variable, $l$ is the length of root, and $r(i)$ is the radius of $i$ th subcylinder. $F_{\mathrm{d}}(i)$ is the flux due to diffusion, $F_{\mathrm{m}}(i)$ is the flux due to mass flow and $S(i)$ is the amino acid supply rate at the surface of $i$ th subcylinder (Fig. 2). $S(i)$ defines how many amino acid molecules are produced within the rhizosphere, while $F_{\mathrm{d}}(i)$ and $F_{\mathrm{m}}(i)$ define how many amino acid molecules are transported towards the root surface. The concentration of soil amino acid $\mathrm{N}_{\mathrm{AC}}$ is the leftover amino acid since microbes have already taken enough organic nitrogen through the process of NUPTAKE_MI in Eq. (8).

The change in the exchangeable concentration of amino acids $(\Delta C)$ in the $i$ th subcylinder is $\left(\Delta C(i)=\frac{\Delta N(i)}{\pi l \Delta\left(r^{2}\right)}\right)$. The denominator is the subcylinder volume. We assume the change of actual amino acid concentration $\left(\Delta C_{1}\right)$ is proportional to the change of exchangeable amino acid concentration $\left.\left(\Delta C_{1}(i)=\frac{\Delta N(i)}{b \pi l \Delta\left(r^{2}\right)}\right)\right)$. The proportion parameter $b$ is a constant. Then we have

$$
\frac{\Delta C_{1}(i)}{\Delta t}=\frac{2 \Delta\left(r F_{\mathrm{d}}\right)+2 \Delta\left(r F_{\mathrm{m}}\right)+\Delta\left(r^{2}\right) S(i)}{b \Delta\left(r^{2}\right)} .
$$

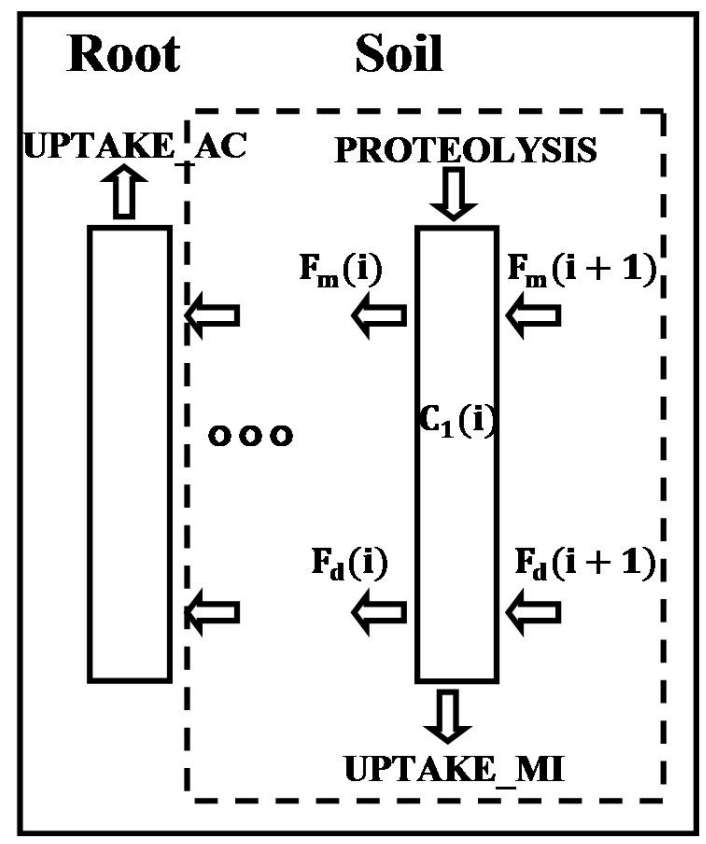

Fig. 2. Schematic representation of modeling amino acid transportation in soil and uptake by plants: the roots' surrounding soil is divided into many thin subcylinders. This is a vertical slice picture of $i$ th sub-cylinder from the root surface. $C_{1}(i)$ is concentration of amino acid in soil solution in the subcylinder. $F_{\mathrm{m}}(i)$ and $F_{\mathrm{d}}(i)$ are mass flow and diffusion of amino acid, respectively. The supply rate of amino acid is calculated by the discrepancy between proteolysis and microbial uptake (Lipson et al., 2001).

The diffusion $F_{\mathrm{d}}$ is calculated using the first order Fick's law; the mass flow $F_{\mathrm{m}}$ is estimated by water flow:

$F_{\mathrm{d}}(i)=-D_{\mathrm{e}} b \frac{C_{1}(i-1)-C_{1}(i)}{\Delta r}$

$F_{\mathrm{m}}(i)=C_{1}(i) v(i)$

where $D_{\mathrm{e}}$ is the effective diffusion coefficient of a nutrient through the soil medium and $v(i)$ is the volume of water moving across the cylinder boundary. We assume that the total water flux at any boundary must be equal to the flux at the root surface, so we have $v(i)=v_{0}$.

At the surface of the root, the amino acid uptake rate $I_{n}$ is modeled with Michaelis-Menten kinetics:

$I_{n}=I_{\max } \frac{\left(C_{1}(1)-C_{\min }\right)}{K_{\mathrm{m}}+\left(C_{1}(1)-C_{\min }\right)}$

where $C_{1}(1)$ is the soil solution amino acid concentration at the root surface, and $C_{\min }$ is the $C_{1}(1)$ at which point uptake is zero. Initializing the amino acid concentration with $C_{0}$, and assuming that all the soil subcylinders are homogeneous, results in $C_{1}(i)=C_{0}(i \in[1 n])$. With the boundary condition $F_{\mathrm{d}}(n+1)=0$ and $F_{\mathrm{m}}(n+1)=0$, the differential Eq. (6) can be numerically solved. To conserve organic nitrogen in the system, we assume (1) there is no leaching of 
amino acids, and (2) the modeled amino acid uptake is the "potential" nitrogen uptake. Plant takes inorganic nitrogen first, and if inorganic nitrogen is not enough for plant survival and growth, it would use amino acids to meet its demand. The rest of the amino acids ("potential" amino acid uptake minus actual amino acid uptake) will be distributed back into soils.

\subsection{Data}

The climate forcing data are monthly averaged reanalysis climate data from NCEP, including air temperature, cloudiness and precipitation (Kalnay et al., 1996) from 1948 to 2010. The global averaged atmosphere $\mathrm{CO}_{2}$ concentration data are observations at Mauna Loa, Hawaii (Conway et al., 1994; Masarie and Tans, 1995). We use the monthly gapfilled (level-4) AmeriFlux NEP and GPP to parameterize and validate the TEM and ON-TEM with their adjoint versions (Zhu and Zhuang, 2013). The information of four sites covering wet tundra and boreal forest ecosystems are documented in Table 1.

\subsection{Parameterization}

We first parameterized TEM using its adjoint version Adjoint-TEM (Zhu and Zhuang, 2013) for an arctic tundra site and a boreal forest site. Model parameters (Table 2) were calibrated in such a way that (1) the simulated carbon fluxes get close to observations, and (2) the optimal parameters are within their prior range so that they are ecologically meaningful. US-Brw $\left(-156.6^{\circ}, 71.32^{\circ}\right)$ site has a low growing temperature, short growing season, frozen soil and shallow water table depth. We classified this site as "wet/moist tundra" in the TEM vegetation classification scheme. The GPP and NEP data of 1999 were used to parameterize the model and the 2001 data were used for model evaluation. Site UCI $1998\left(-99.95^{\circ}, 56.63^{\circ}\right)$ with a boreal climate that is extremely cold in winter and mild to warm in summer was classified as evergreen conifer forest (IGBP classification; Loveland and Belward, 1997). This site was classified as "boreal forest" ecosystem in TEM. GPP and NEP data from 2002 to 2005 were assimilated into TEM. The optimized parameters were then applied to two other boreal forest sites, UCI 1989 $\left(-98.96^{\circ}, 55.92^{\circ}\right)$ and UCI $1850\left(-94.48^{\circ}, 55.88^{\circ}\right)$, to verify model parameterization.

Next, we parameterized ON-TEM for arctic tundra and boreal forest using the same approach and the same observational data. ON-TEM introduced a new nitrogen pool, three new fluxes (Fig. 1) and several new parameters (Table 3). Initial value of the amino acid pool size $\left(\mathrm{N}_{\mathrm{AC}}\right)$ was derived from the measured seasonal mean amino acid pool size at an alpine site (Lipson et al., 2001). The soil amino acid transformationrelated parameters (e.g., $P Q_{10}$, AMOIST) were estimated based on a study on a typical amino acid glutamate (glu). The glu is used as representative amino acid type in estimating the parameters because the microbial uptake of glu is similar to many other amino acids types (Lipson et al., 1999). Thus, the obtained parameters could be used for modeling general amino acid uptake by plants without specifying the types of amino acids. One difference is that the Lipson et al. (1999) study focused on alpine tundra soils, while our focus was on arctic tundra and boreal forests. The differences in both climate and soil conditions between alpine tundra and boreal forests might introduce uncertainty in estimating amino acid availability in soils. Therefore we conducted an uncertainty analysis on these parameters. The root uptake kineticsrelated parameters were derived from a modeling study at an arctic sedge site (Table 3; Leadley et al., 1997). Only parameters listed in Table 2 are optimized for ON-TEM. Parameters listed in Table 3 are directly derived from previous studies, which are fixed in ON-TEM. As a supplement, we conducted an analysis to investigate how much uncertainties in model outputs are induced by the uncertainty in these parameters from Table 3.

\subsection{Sensitivity study}

A sensitivity analysis focusing on organic nitrogen uptake dynamics will help identify which process is more important in regulating organic nitrogen uptake. We grouped the factors and processes in controlling organic nitrogen uptake into four categories (Table 4): (1) amino acid supply factors, including the initial amino acid pool size and its change due to proteolysis and microbial uptake; (2) soil factors, which include the Fick's law diffusion coefficient for amino acids through soils as well as the water flux at root surface; (3) root factors, including the radius of root, the radius of the soil cylinder surrounding the root; and (4) plant uptake kinetics factors, which include the maximum and half-saturation root uptake rate of Michaelis-Menten kinetics.

The sensitivity study was achieved by using a variancebased global sensitivity technique based on SOBOL sampling (Pappas et al., 2013). It samples the prespecified full parameter space (Table 4) by conducting ensemble simulations. The changes in output variables are then decomposed and attributed to each control parameter. One of the most important measures of model sensitivity is the first order sensitivity index $S_{\mathrm{i}}$ (or main effect index). It quantifies how much output variance is contributed by $i$ th parameter alone, averaged over the other parameters as follows:

$S_{\mathrm{i}}=\frac{\operatorname{Var}_{p_{i}}\left[E_{p_{\sim i}}\left(\mathrm{ON}_{\mathrm{up}} \mid p_{i}\right)\right]}{\operatorname{Var}\left(\mathrm{ON}_{\mathrm{up}}\right)}$,

where $\mathrm{ON}_{\text {up }}$ is the simulated organic nitrogen uptake, $p_{i}$ is the tested parameter, and $p_{\sim i}$ represents all other parameters except the tested parameter $p_{i} . E$ and Var are statistical expectation and variance. The first order sensitivity index $S_{\mathrm{i}}$ provides us a criterion to rank the relative importance of each specific parameter of interest. 
Table 1. Information of AmeriFlux sites used in the study.

\begin{tabular}{|c|c|c|c|c|}
\hline ID & $\begin{array}{l}\text { Vegetation } \\
\text { type }\end{array}$ & $\begin{array}{l}\text { Available } \\
\text { data }\end{array}$ & PI & Reference \\
\hline US-Brw & Wet tundra & 1999, 2001 & Oechel W. C. & $\begin{array}{l}\text { Owen et al. (2007), } \\
\text { Eugster et al. (2000) }\end{array}$ \\
\hline UCI 1998 & Boreal forest & 2002-2005 & Goulden M. L. & $\begin{array}{l}\text { Goulden et al. (2011), } \\
\text { Bond-Lamberty et al. (2004) }\end{array}$ \\
\hline UCI 1989 & Boreal forest & 2001-2005 & Goulden M. L. & $\begin{array}{l}\text { Goulden et al. (2011), } \\
\text { Wang et al. (2003) }\end{array}$ \\
\hline UCI 1850 & Boreal forest & 2002-2005 & Goulden M. L. & $\begin{array}{l}\text { Goulden et al. (2011), } \\
\text { Saito et al. (2009) }\end{array}$ \\
\hline
\end{tabular}

Table 2. Optimized parameters in TEM and ON-TEM.

\begin{tabular}{|c|c|c|c|c|c|c|c|c|}
\hline ID & Acronym & Definition & Units & Prior range & $\begin{array}{l}\text { TEM } \\
\text { Tundra }\end{array}$ & $\begin{array}{l}\text { ON-TEM } \\
\text { Tundra }\end{array}$ & $\begin{array}{l}\text { TEM } \\
\text { Boreal } \\
\text { forest }\end{array}$ & $\begin{array}{l}\text { ON-TEM } \\
\text { Boreal } \\
\text { forest }\end{array}$ \\
\hline 1 & $C_{\max }$ & Maximum rate of photosynthesis $\mathrm{C}$ & $\mathrm{gC} \mathrm{m}^{-2}$ month $^{-1}$ & {$[50,1500]$} & 399.3 & 341.4 & 853.8 & 568.7 \\
\hline 2 & $K_{\mathrm{I}}$ & $\begin{array}{l}\text { Half-saturation constant for PAR } \\
\text { used by plants }\end{array}$ & $\mathrm{J} \mathrm{cm}^{-2}$ day $^{-1}$ & {$[20,600]$} & 33.2 & 72.4 & 215.5 & 289.5 \\
\hline 3 & $K_{\mathrm{C}}$ & $\begin{array}{l}\text { Half-saturation constant for } \mathrm{CO}_{2}-\mathrm{C} \\
\text { uptake by plants }\end{array}$ & $\mu \mathrm{LL}^{-1}$ & {$[20,600]$} & 53.0 & 144.4 & 286.0 & 531.6 \\
\hline 4 & ALEAF & $\begin{array}{l}\text { Coefficient } A \text { to model the relative } \\
\text { photosynthetic capacity of vegetation }\end{array}$ & None & {$[0.1,1.0]$} & 0.8066 & 0.8179 & 0.4452 & 0.4987 \\
\hline 5 & BLEAF & $\begin{array}{l}\text { Coefficient } B \text { to model the relative } \\
\text { photosynthetic capacity of vegetation }\end{array}$ & None & {$[0.1,1.0]$} & 0.5148 & 0.4663 & 0.4216 & 0.4061 \\
\hline 6 & CLEAF & $\begin{array}{l}\text { Coefficient } C \text { to model the relative } \\
\text { photosynthetic capacity of vegetation }\end{array}$ & None & {$[0.0,0.5]$} & 0.0300 & 0.0287 & 0.3369 & 0.3228 \\
\hline 7 & $R A Q 10 \mathrm{~A} 0$ & $\begin{array}{l}\text { Leading coefficient of the } Q 10 \\
\text { model for plant respiration }\end{array}$ & None & $\begin{array}{l}{[1.350} \\
3.3633]\end{array}$ & 3.2661 & 2.3566 & 1.4041 & 1.8011 \\
\hline 8 & $\mathrm{KDC}$ & Heterotrophic respiration rate at $0^{\circ} \mathrm{C}$ & $\mathrm{g} \mathrm{g}^{-1}$ month $^{-1}$ & $\begin{array}{l}{[0.0005,} \\
0.007]\end{array}$ & 0.000686 & 0.001377 & 0.001928 & 0.001694 \\
\hline 9 & RHQ $Q 10$ & $\begin{array}{l}\text { Change in heterotrophic respiration } \\
\text { rate due to } 10^{\circ} \mathrm{C} \text { temperature change }\end{array}$ & None & {$[1,3]$} & 2.04 & 2.01 & 1.96 & 2.03 \\
\hline 10 & $K_{\mathrm{R}}$ & $\begin{array}{l}\text { Logarithm of plant respiration rate } \\
\text { at } 0^{\circ} \mathrm{C}\end{array}$ & None & $\begin{array}{l}{[-7.5} \\
-1.5]\end{array}$ & -1.5228 & -5.7254 & -1.9854 & -2.0106 \\
\hline
\end{tabular}

The ranges (upper and lower bounds) of the tested parameters were derived from previous studies (see Table 4 and references herein). Since we have no prior knowledge about the distributions of these parameters, we assumed they were uniformly distributed within their upper and lower bounds. Such an assumption is common practice and is adopted by other studies when prior knowledge about parameter distribution is lacking (Zaehle et al., 2005; Pappas et al., 2013).

\subsection{Uncertainty analysis}

The organic nitrogen uptake parameters' values (Table 3) are from other studies (Leadley et al., 1997; Lipson et al., 2001). This could introduce a great deal of uncertainties to the coupled model simulations. To quantify the influence of uncertainties from the organic nitrogen uptake associated parameters in ON-TEM, we conducted an uncertainty analysis with ensemble simulations. Each ensemble used a set of pa- rameters that were independently sampled from the parameter space. Specifically, we assumed the organic nitrogen uptake parameters $(p)$ were distributed within $[0.9 p, 1.1 p]$, in which a $\pm 10 \%$ of parameter uncertainty was enforced. The parameters were sampled uniformly from the range $[0.9 p$, $1.1 \mathrm{p}$ ]. For each parameter we had 100 samples, and only one parameter was perturbed each time. Thus we obtained a large number of parameter sets. Each parameter set represented a model with a unique uncertainty in parameter space, and was used to simulate carbon and nitrogen fluxes of GPP, NEP, organic nitrogen uptake and total nitrogen uptake for the analysis. 
Table 3. New parameters introduced in ON-TEM.

\begin{tabular}{|c|c|c|c|c|}
\hline $\begin{array}{l}\text { Variables } \\
\text { parameters }\end{array}$ & Variables and parameters description & Units & value & reference \\
\hline \multicolumn{5}{|c|}{ Soil amino acids transformation related } \\
\hline$N_{\mathrm{AC}}$ & Soil amino acid initial concentration & $\mathrm{nmolg}^{-1}$ & 265 & Lipson et al. (2001) \\
\hline$P$ & Proteolysis rate in soil & $\mathrm{nmol} \mathrm{g}^{-1} \mathrm{~h}^{-1}$ & 32.8 & Lipson et al. (2001) \\
\hline$R$ & First order microbial amino acid uptake rate & $\mathrm{h}^{-1}$ & 0.111 & Lipson et al. (2001) \\
\hline$R Q 10$ & Soil microbial amino acid uptake $Q 10$ & - & 2.57 & Lipson et al. (2001) \\
\hline$P Q 10$ & Soil proteolysis $Q 10$ & - & 1.98 & Lipson et al. (2001) \\
\hline AMOIST & Coefficient of moist effect on microbial amino acid uptake rate & - & 4.82 & Lipson et al. (2001) \\
\hline BMOIST & Coefficient of moist effect on microbial amino acid uptake rate & - & -9.78 & Lipson et al. (2001) \\
\hline CMOIST & Coefficient of moist effect on microbial amino acid uptake rate & - & 6.93 & Lipson et al. (2001) \\
\hline DMOIST & Coefficient of moist effect on microbial amino acid uptake rate & - & -0.69 & Lipson et al. (2001) \\
\hline \multicolumn{5}{|c|}{ Root uptake kinetics related } \\
\hline$r_{0}$ & Radius of root & $\mathrm{cm}$ & 0.04 & Leadley et al. (1997) \\
\hline$r_{1}$ & Radius of rhizosphere soil cylinder & $\mathrm{cm}$ & 0.35 & Leadley et al. (1997) \\
\hline$C_{\min }$ & Soil solution concentration at which root uptake is zero & $\operatorname{mmol~cm}{ }^{-3}$ & 0.0 & Leadley et al. (1997) \\
\hline$D_{\mathrm{e}}$ & First order Fick's law diffusion coefficient & $\mathrm{cm}^{2} \mathrm{~s}^{-1}$ & $1.0 \times 10^{-6}$ & Leadley et al. (1997) \\
\hline$b$ & Soil buffer capacity & - & 3.0 & Leadley et al. (1997) \\
\hline$I_{\max }$ & Maximum root uptake rate & $\mathrm{mmol} \mathrm{cm}{ }^{-2} \mathrm{~s}^{-1}$ & $1.0 \times 10^{-9}$ & Leadley et al. (1997) \\
\hline$K_{\mathrm{m}}$ & Half-saturation constant for root uptake kinetics & $\mathrm{mmol} \mathrm{cm}{ }^{-3}$ & $2.0 \times 10^{-5}$ & Leadley et al. (1997) \\
\hline$v_{0}$ & Water flux at the root surface & $\mathrm{cm} \mathrm{s}^{-1}$ & $5.0 \times 10^{-8}$ & Leadley et al. (1997) \\
\hline
\end{tabular}

Table 4. Upper and lower bounds of the selected parameters for the global sensitivity analysis.

\begin{tabular}{|c|c|c|c|c|c|}
\hline $\begin{array}{l}\text { Selected } \\
\text { parameters }\end{array}$ & $\begin{array}{l}\text { Testing } \\
\text { factors }\end{array}$ & Unit & $\begin{array}{l}\text { Upper } \\
\text { bound }\end{array}$ & $\begin{array}{l}\text { Lower } \\
\text { bound }\end{array}$ & References \\
\hline$P$ (proteolysis rate in soil) & $\begin{array}{l}\text { Supply } \\
\text { factors }\end{array}$ & $\mathrm{nmolg}^{-1} \mathrm{~h}^{-1}$ & 55 & 10 & Lipson et al. (2001) \\
\hline $\begin{array}{l}R \text { (first order microbial } \\
\text { amino acid uptake rate) }\end{array}$ & $\begin{array}{l}\text { Supply } \\
\text { factors }\end{array}$ & $\mathrm{h}^{-1}$ & 0.43 & 0.048 & Lipson et al. (2001) \\
\hline $\begin{array}{l}\mathrm{N}_{\mathrm{AC}} \text { ( soil amino acid } \\
\text { initial concentration) }\end{array}$ & $\begin{array}{l}\text { Supply } \\
\text { factors }\end{array}$ & $\mathrm{nmol} \mathrm{g}^{-1}$ & $2.8 \times 10^{4}$ & $1.7 \times 10^{3}$ & $\begin{array}{l}\text { Kielland et al. (2007). } \\
\text { Given in unit }\left(\mu \mathrm{g} \mathrm{g}^{-1}\right)^{\mathrm{a}}\end{array}$ \\
\hline $\begin{array}{l}D_{\mathrm{e}} \text { (first order Fick's } \\
\text { law diffusion coefficient) }\end{array}$ & $\begin{array}{l}\text { Soil } \\
\text { factors }\end{array}$ & $\mathrm{cm}^{2} \mathrm{~s}^{-1}$ & $7.0 \times 10^{-6}$ & $5.0 \times 10^{-7}$ & Leadley et al. (1997) \\
\hline $\begin{array}{l}v_{0} \text { (water flux at the } \\
\text { root surface) }\end{array}$ & $\begin{array}{l}\text { Soil } \\
\text { factors }\end{array}$ & $\mathrm{cm} \mathrm{s}^{-1}$ & $5.0 \times 10^{-7}$ & $1.0 \times 10^{-8}$ & Leadley et al. (1997) \\
\hline$r_{0}$ (radius of root) & $\begin{array}{l}\text { Root } \\
\text { factors }\end{array}$ & $\mathrm{cm}$ & 0.07 & 0.0035 & Leadley et al. (1997) \\
\hline $\begin{array}{l}r_{1} \text { (radius of } \\
\text { rhizosphere soil cylinder) }\end{array}$ & $\begin{array}{l}\text { Root } \\
\text { factors }\end{array}$ & $\mathrm{cm}$ & 0.5 & 0.2 & Leadley et al. (1997) \\
\hline $\begin{array}{l}I_{\max }(\text { maximum root } \\
\text { uptake rate) }\end{array}$ & $\begin{array}{l}\text { Plant } \\
\text { uptake } \\
\text { kinetics }\end{array}$ & $\mathrm{mmol} \mathrm{cm}{ }^{-2} \mathrm{~s}^{-1}$ & $2.1 \times 10^{-8}$ & $1.0 \times 10^{-10}$ & $\begin{array}{l}\text { Lipson and Nasholm (2001). } \\
\text { Given in unit }\left(\mu \mathrm{mol} \mathrm{g}^{-1} \mathrm{~h}^{-1}\right)^{\mathrm{b}}\end{array}$ \\
\hline $\begin{array}{l}K_{\mathrm{m}} \text { (half-saturation } \\
\text { constant for root uptake } \\
\text { kinetics) }\end{array}$ & $\begin{array}{l}\text { Plant } \\
\text { uptake } \\
\text { kinetics }\end{array}$ & $\mathrm{mmol} \mathrm{cm}{ }^{-3}$ & $1.3 \times 10^{-2}$ & $1.6 \times 10^{-6}$ & $\begin{array}{l}\text { Lipson and Nasholm }(2001) \text {. } \\
\text { Given in unit }(\mu \mathrm{mol} \mathrm{L}-1)^{c}\end{array}$ \\
\hline
\end{tabular}




\section{Results and discussion}

\subsection{TEM and ON-TEM simulations at site level}

Optimized parameters were greatly different after we incorporated the organic nitrogen uptake kinetics into TEM to create ON-TEM. For example, at the tundra site USBrw, the parameter $C_{\max }$ (the maximum rate of photosynthesis) was $341.4 \mathrm{~g} \mathrm{C} \mathrm{m}^{-2}$ month $^{-1}$ for ON-TEM and $399.3 \mathrm{~g} \mathrm{C} \mathrm{m}^{-2}$ month $^{-1}$ for TEM. $K_{\mathrm{I}}$ (half-saturation constant for PAR used by plants) and $K_{\mathrm{C}}$ (half-saturation constant for $\mathrm{CO}_{2}-\mathrm{C}$ uptake by plants) were $72.4 \mathrm{~J} \mathrm{~cm}^{-2}$ day $^{-1}$ and $144.4 \mu \mathrm{LL}^{-1}$ for ON-TEM and $33.2 \mathrm{~J} \mathrm{~cm}^{-2} \mathrm{day}^{-1}$ and $53.0 \mu \mathrm{LL}^{-1}$ for TEM, respectively. Original TEM required a higher carbon photosynthesis rate and lower half-saturation constants so that it is able to produce higher carbon fluxes (e.g., GPP, NEP) under the same nitrogen-limited environmental conditions.

The optimal parameters were estimated for both TEM and ON-TEM (Table 2). We ran both TEM and ON-TEM (1) at the US-Brw site in 2001 using parameters calibrated with US-Brw data in 1999; and (2) at the UCI 1989 and UCI 1850 sites using parameters calibrated at the UCI 1998 site to evaluate the goodness of models and parameters. Model results were compared with observational GPP and NEP (Fig. 3ad). TEM assumes that plants can only utilize inorganic nitrogen in the soil, and inorganic nitrogen is usually limited in at boreal forest and tundra ecosystems. As a result, TEM underestimated GPP and NEP, especially during the growing season (June-September). Although TEM had higher $C_{\max }$ and lower half-saturation points for $\mathrm{CO}_{2}-\mathrm{C}$ uptake and photosynthetic active radiation compared with ON-TEM, it was still unable to produce the observed carbon fluxes during the growing season. It indicated that TEM tended to underestimate GPP and NEP because of the nitrogen limitation rather than the underestimated $C_{\max }$ or overestimated $K_{\mathrm{I}} / K_{\mathrm{C}}$. In contrast, ON-TEM was able to produce relatively higher carbon fluxes and captured the seasonal variation and magnitude of both GPP and NEP. However, ON-TEM still underestimated NEP, although the underestimations were not as much as those by TEM. In general, ON-TEM reproduced AmeriFlux observations better than TEM (both linear regression $R^{2}$ and slope are closer to one) (Table 5). We also found that both TEM and ON-TEM simulate GPP better at boreal forest sites $\left(R^{2}: 0.93,0.81,0.79\right.$ for ON-TEM and 0.87, 0.76, 0.77 for TEM) than at the tundra site $\left(R^{2}: 0.60\right.$ for ON-TEM and 0.54 for TEM). Both ON-TEM and TEM were able to better simulate GPP than NEP. That is because GPP is much easier to constrain than NEP. GPP has only one process that is involved. When modeling NEP, both plant respiration and soil respiration in addition to plant photosynthesis are involved.

The implication of these ON-TEM is that plants will take up organic forms of nitrogen when inorganic nitrogen is limited. Organic nitrogen plays a less significant role in boreal forests than it does in tundra (Chapin et al., 1993; Nasholm et
Table 5. Statistics interpretation for model-data fitting (in Fig. 3), which includes the linear regression slope, the Pearson correlation coefficient $\left(R^{2}\right)$ and the significance of the Pearson correlation coefficient ( $p$ value).

\begin{tabular}{lllll}
\hline site & \multicolumn{1}{c}{ GPP } & \multicolumn{2}{c}{ NEP } \\
& \multicolumn{1}{c}{$R^{2}(p$ value $)$} & slope & $R^{2}(p$ value $)$ & slope \\
\hline \multicolumn{2}{c}{ ON-TEM versus AmeriFlux } & & & \\
\hline US-Brw & $0.60(0.019)$ & 0.95 & $0.64(0.012)$ & 0.74 \\
UCI 1998 & $0.93\left(<10^{-5}\right)$ & 1.17 & $0.29(0.022)$ & 0.67 \\
UCI 1989 & $0.81\left(<10^{-5}\right)$ & 0.98 & $0.56\left(<10^{-5}\right)$ & 0.60 \\
UCI 1850 & $0.79\left(<10^{-5}\right)$ & 0.93 & $0.64\left(<10^{-5}\right)$ & 0.61 \\
\hline TEM versus AmeriFlux & & & \\
\hline US-Brw & $0.54(0.034)$ & 0.57 & $0.58(0.024)$ & 0.37 \\
UCI 1998 & $0.87\left(<10^{-5}\right)$ & 0.98 & $-0.082(0.28)$ & 0.30 \\
UCI 1989 & $0.76\left(<10^{-5}\right)$ & 0.83 & $0.26(0.022)$ & 0.37 \\
UCI 1850 & $0.77\left(<10^{-5}\right)$ & 0.76 & $0.27(0.031)$ & 0.31 \\
\hline
\end{tabular}
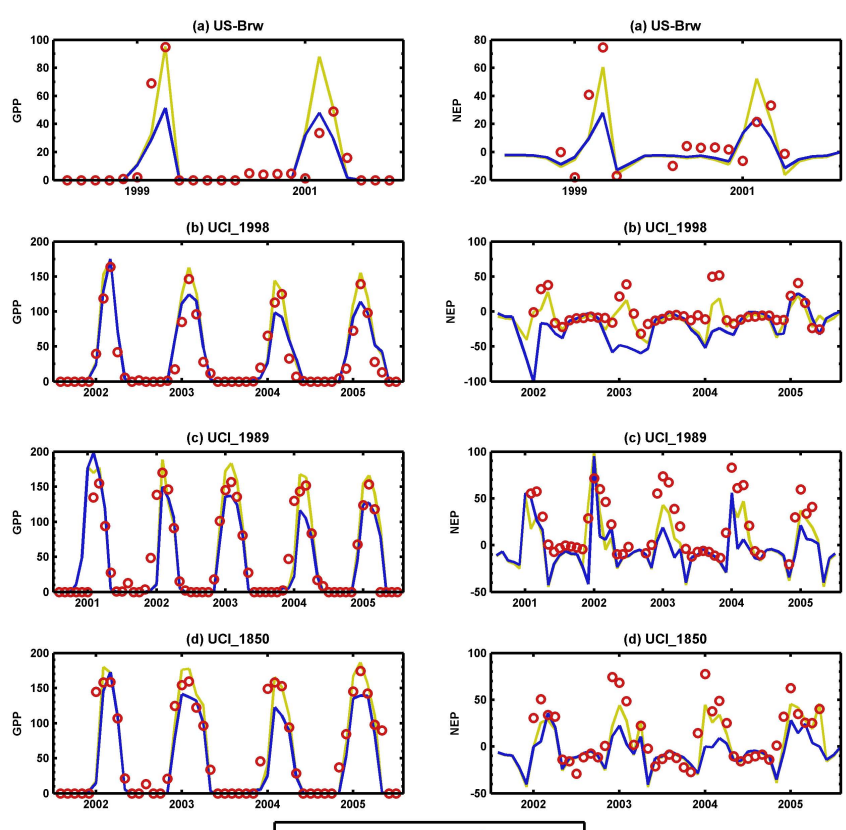

(d) UCl_1850

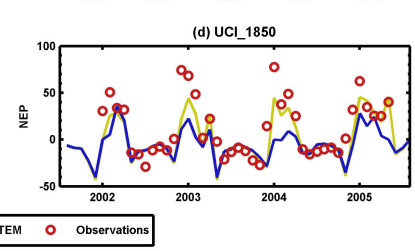

Fig. 3. GPP and NEP $\left(\mathrm{g} \mathrm{C} \mathrm{m}^{-2}\right.$ month $\left.^{-1}\right)$ simulated by ON-TEM; considerations of the organic nitrogen uptake process are represented by the yellow lines. In comparison with the TEM (blue lines), ON-TEM simulations (yellow lines) are generally more consistent with the observations (red circles). (a-d) are the tundra site USBrw and the boreal forest sites UCI 1998, UCI 1989 and UCI 1850, respectively.

al., 1998), since the inorganic nitrogen in tundra soils is much more limited. Our model simulations indicated that, at tundra sites, organic forms of nitrogen accounted for 36-87\% of the total nitrogen uptake; for boreal forests, organic nitrogen only accounted for $26-50 \%$ of the total uptake (Table 6). Overall, the total amount of organic nitrogen used by boreal 
forest was $0.45 \mathrm{~g} \mathrm{~N} \mathrm{~m}^{-2}$ month $^{-1}$ averaged for four months at all three sites, which was greater than that by tundra averaged for four months at US-Brw $\left(0.15 \mathrm{~g} \mathrm{~N} \mathrm{~m}^{-2} \mathrm{month}^{-1}\right)$.

\subsection{Sensitivity study}

To understand the effects of controlling factors on plant uptake of organic nitrogen in ON-TEM, we conducted a sensitivity analysis for the organic $\mathrm{N}$ uptake module. We found that the magnitudes of the first order sensitivity index $\left(S_{\mathrm{i}}\right)$ follow the order $D_{\mathrm{e}}>r_{1} \gg r_{0}>I_{\max } \gg$ others (Fig. 4). Our results showed that the most sensitive parameter was $D_{e}$ (First order Fick's law diffusion coefficient), suggesting that the organic nitrogen uptake process was regulated or limited by how fast the amino acids diffuse through the soil media. This finding is consistent with the prevailing idea that organic $\mathrm{N}$ uptake is primarily controlled by soil characteristics, especially diffusion rate of nutrient through soil, due to the strong interactions between free amino acid and soil matrix (Jones and Darrah, 1994; Tinker and Nye, 2000; Lipson and Nasholm, 2001; Nasholm et al., 2009). The other two most sensitive parameters belong to the root factor category: the radius of soil cylinder $\left(r_{1}\right)$ and the radius of root $\left(r_{0}\right)$. These two parameters define the outer and inner boundaries for soil amino acids transportation. Because amino acids availability for plant uptake can be described by the amount of amino acids that are transported to the root surface, it is reasonable that the results reveal that both transport velocity (diffusion rate) and transport distance (distance between outer and inner boundaries) control the amino acids availability.

A secondary important factor that controls plant amino acids acquisition is the maximum root uptake rate $\left(I_{\max }\right)$, which belongs to the category of plant uptake kinetics. In our model we assumed that as long as the amino acids were transported to the root surface, they were readily taken up by plant. As described in Eq. (17), the uptake rate is controlled by maximum uptake rate $\left(I_{\max }\right)$, half-saturation constant $\left(K_{\mathrm{m}}\right)$ and the instantaneous amino acids concentration at root surface $\left(C_{1}(1)\right)$. We found that (1) the instantaneous amino acids concentration (determined by amino acids diffusion) exerted the primary control on plant amino acids uptake, (2) $I_{\max }$ was the secondary control, and (3) the importance of $K_{\mathrm{m}}$ is trivial and could be neglected.

The model was also insensitive to some selected model parameters, for example, the initial concentration $\left(\mathrm{N}_{\mathrm{AC}}\right)$. This is because the actual pool size of organic nitrogen depends on the instantaneous soil proteolysis rate, microbe uptake rate and diffusion rate rather than the initial estimation. The instantaneous rates were usually high enough so that the existent organic nitrogen pool was quickly replaced by newly produced organic nitrogen and the initial pool of organic nitrogen is quickly turned over (e.g., Kielland et al., 2007).

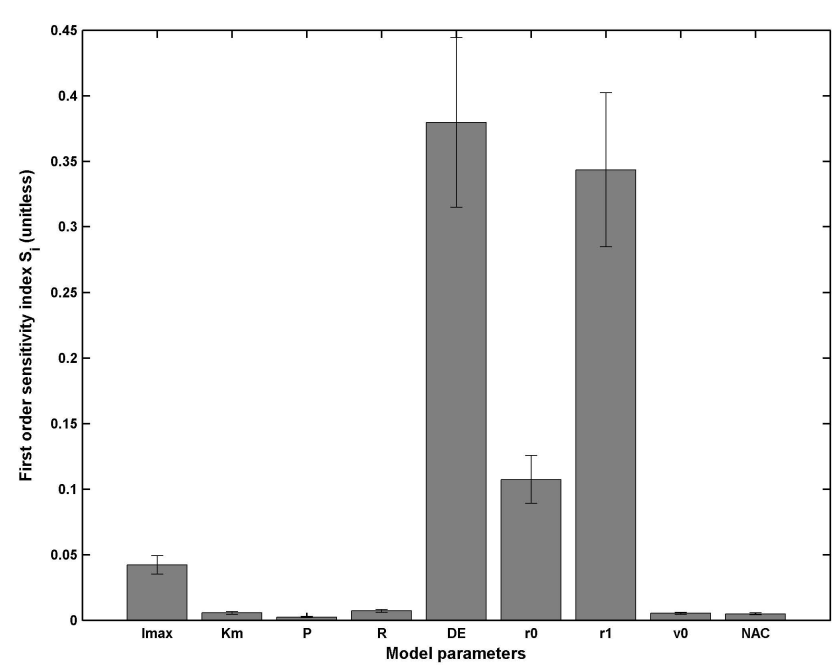

Fig. 4. The mean and standard deviation of the first order sensitivity index $\left(S_{\mathrm{i}}\right)$ of organic nitrogen uptake by plants with respect to each selected controlling parameter (Table 4).

\subsection{Uncertainty analysis}

The organic nitrogen uptake module is the essential component of ON-TEM. It provides the potential amount of organic nitrogen taken up by plants. We conducted an uncertainty analysis using ON-TEM at US-Brw and UCI 1998 site, aiming to quantify the uncertainties in modeling carbon and nitrogen fluxes associated with uncertain organic nitrogen uptake module parameters. We allowed the new parameters introduced in ON-TEM (Table 3) to randomly vary with a magnitude of $\pm 10 \%$, and compared the changes in carbon and nitrogen fluxes.

We found that, at both boreal forest and tundra sites, the changes of the two nitrogen fluxes induced by the changes of parameters were large (Fig. 5). This meant that the uncertainty in organic nitrogen uptake module had a strong effect on the system nitrogen dynamics. However, for carbon fluxes, only at the tundra site (Fig. 5a) (not at the boreal forest site: Fig. 5b) did the parameters uncertainty affect GPP and NEP. Our analysis indicated that, in boreal forests, the amount of organic nitrogen provided by the soil exceeded the actual need of organic nitrogen by the plants. The changes in the selected model parameters altered the organic nitrogen supply but had trivial influence on the actual uptake.

\section{Summary and concluding remarks}

In this study, we incorporated an organic nitrogen uptake mechanism into the process-based terrestrial ecosystem model (TEM) to develop a new version of TEM (ON-TEM). We used the AmeriFlux GPP and NEP data to parameterize and verify both versions of the model. We found that ONTEM simulations were more consistent with the observations 
Table 6. The amount of organic nitrogen uptake and inorganic nitrogen uptake by plants during growing season (June-September) at the four sites modeled by ON-TEM.

\begin{tabular}{lllll}
\hline ID & June & July & August & September \\
\hline \multicolumn{4}{l}{ Organic nitrogen uptake $\left(\mathrm{g} \mathrm{N} \mathrm{m}^{-2} \mathrm{month}^{-1}\right)$} \\
\hline US-Brw & $0.28 \pm 0.067$ & $0.14 \pm 0.062$ & $0.13 \pm 0.062$ & $0.037 \pm 0.011$ \\
UCI 1998 & $0.28 \pm 0.1$ & $0.48 \pm 0.08$ & $0.49 \pm 0.09$ & $0.45 \pm 0.016$ \\
UCI 1989 & $0.46 \pm 0.006$ & $0.48 \pm 0.001$ & $0.48 \pm 0.001$ & $0.46 \pm 0.012$ \\
UCI 1850 & $0.46 \pm 0.006$ & $0.48 \pm 0.002$ & $0.48 \pm 0.002$ & $0.47 \pm 0.001$ \\
\hline Inorganic nitrogen uptake $\left(\mathrm{g} \mathrm{N} \mathrm{m}^{-2}\right.$ month $\left.^{-1}\right)$ & \\
\hline US-Brw & $0.04 \pm 0.08$ & $0.24 \pm 0.01$ & $0.23 \pm 0.01$ & $0.035 \pm 0.005$ \\
UCI 1998 & $0.79 \pm 0.08$ & $0.99 \pm 0.01$ & $0.87 \pm 0.04$ & $0.66 \pm 0.032$ \\
UCI 1989 & $0.46 \pm 0.06$ & $0.89 \pm 0.05$ & $0.66 \pm 0.12$ & $0.53 \pm 0.085$ \\
UCI 1850 & $0.47 \pm 0.06$ & $0.91 \pm 0.05$ & $0.67 \pm 0.13$ & $0.54 \pm 0.092$ \\
\hline
\end{tabular}

in comparison with the original TEM. ON-TEM could better quantify carbon cycling of boreal forest and tundra ecosystems, particularly when considering organic nitrogen uptake. In ON-TEM simulations, organic nitrogen contributed 36$87 \%$ and $26-50 \%$ of total nitrogen uptake at the tundra and boreal forest sites, respectively, suggesting that the tundra ecosystem (vs. that of the boreal forest) likely relies more on the organic form of nitrogen. These results were consistent with the findings of Nasholm et al. (1998), who stated that at least $42 \%$ nitrogen uptake was from the organic form of nitrogen for trees in boreal forests. Further, we explored the sensitivity of the modeled organic nitrogen uptake to nine selected parameters. We found that the soil factor of $D_{\mathrm{e}}$ (first order Fick's law diffusion) and the root factors of $r_{0}$ and $r_{1}$ were the three most sensitive parameters, indicating that plant organic $\mathrm{N}$ uptake was controlled by how fast the amino acids could be transported from outer boundary to root surface through diffusion. The next most sensitive parameter was the uptake kinetics factor of $I_{\max }$. The organic $\mathrm{N}$ uptake module was however much less sensitive to other parameters, such as supply factor of $\mathrm{N}_{\mathrm{AC}}$ (soil amino acid initial concentration) or root factor of $v_{0}$ (water flux at the root surface). Finally, we conducted an uncertainty analysis on the organic nitrogen uptake module. We found that the uncertainty in organic nitrogen uptake module parameters had larger impacts on tundra carbon dynamics than on boreal forest carbon dynamics. We concluded that modeling the effects of organic nitrogen uptake on ecosystem carbon cycling is an important step towards incorporating more detailed organic nitrogen dynamics into ecosystem models.

This study has several limitations. First, ON-TEM has not been incorporated with mycorrhizae effects in the context of organic nitrogen uptake, even though a number of studies (e.g., Kielland et al., 1994) indicate that the mycorrhizae play a significant role in the process of plants taking up soil organic nitrogen. Second, we adopted the parameters from other studies (Leadley et al., 1997; Lipson et al., 2001), which might introduce additional uncertainty. Our analysis indicated that such uncertainty was small at boreal forest sites, but was large at the tundra site. Third, we have not specified the type of amino acid species that are used by plants in ON-TEM. For different ecosystem soils, the plants might take up different types of organic nitrogen. Therefore, modeling the effects of different organic nitrogen compounds is needed for future studies. In addition, the algorithm of soil proteolysis has not explicitly included the substrate limitation effects. For instance, it has been found that the soil proteolysis rate was positively correlated with soil extractable protein content and the total soil nitrogen (Raab et al., 1999). In this study, we made an assumption that plants use inorganic forms of $\mathrm{N}$ first $\left(\mathrm{NH}_{4}^{+}\right.$and $\left.\mathrm{NO}_{3}^{-}\right)$, and utilize organic $\mathrm{N}$ as supplement when the inorganic $\mathrm{N}$ is insufficient. Previous studies have suggested that the root uptake rates of different forms of $\mathrm{N}$ generally follow a certain order: $\mathrm{NH}_{4}^{+}>$amino acids $>\mathrm{NO}_{3}^{-}$(Ohlund and Nasholm, 2001; Thornton and Robinson, 2005). Although our assumption was not fully consistent with previous research, this is an appropriate assumption to make at our current modeling stage because our primary focus was to test if the plant uptake of additional organic form of $\mathrm{N}$ in our model could improve the quantification of ecosystem carbon fluxes.

\section{Appendix A}

\section{Adjoint-TEM parameterization method}

The parameterization of the Terrestrial Ecosystem Model was conducted with an adjoint method (Zhu and Zhuang, 2013). The adjoint data assimilation method adjusts model parameters through minimizing the misfits between the model and data over the spatiotemporal domains. A cost function ( $J$ in Eq. A1) measuring the model-data misfit is defined as a summation of two parts, which are the difference between model parameters and their prior knowledge 

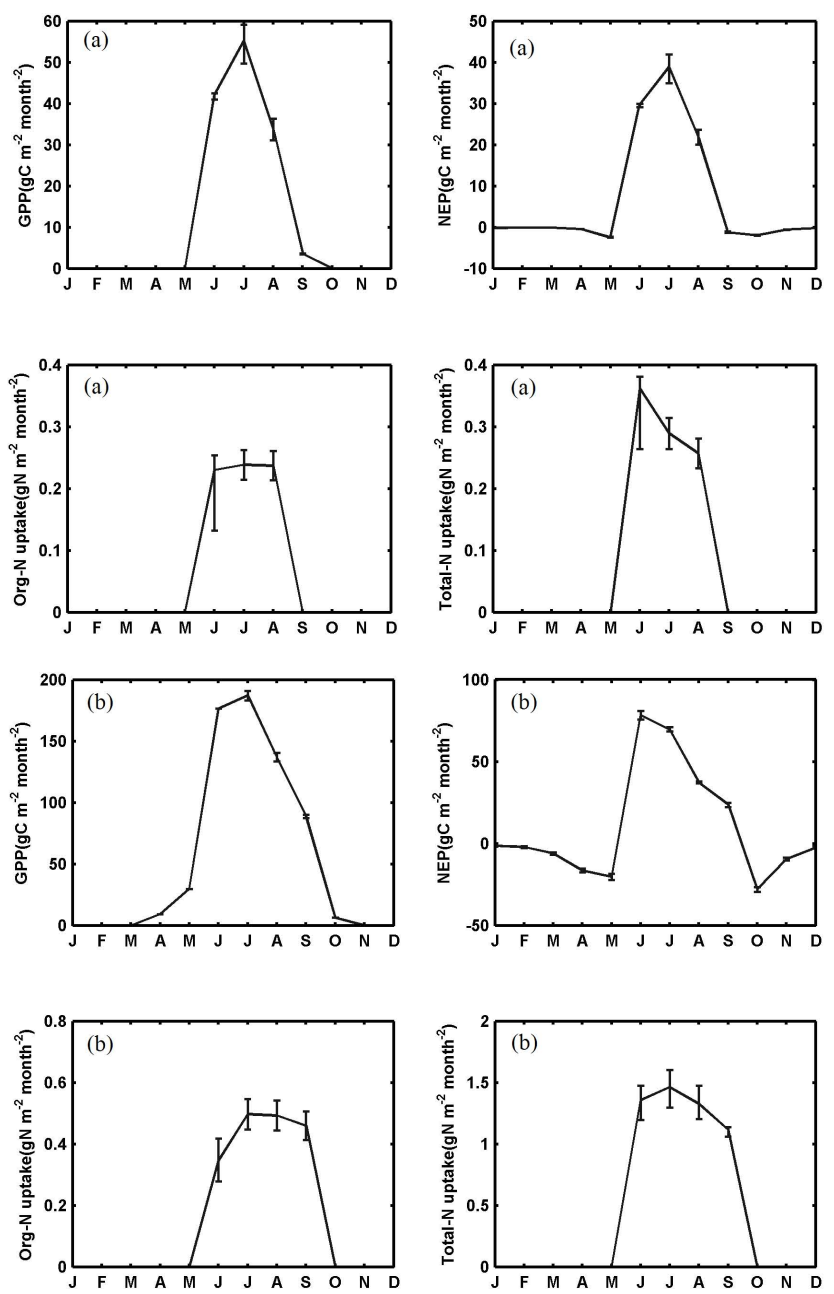

Fig. 5. Uncertainty analysis of the organic nitrogen uptake modulerelated parameters, showing the ensemble simulations mean, upper and lower bounds. GPP, NEP, the organic nitrogen uptake and the total nitrogen uptake are illustrated. (a) is the tundra site US-Brw and (b) is the boreal forest site UCI 1998.

(Eq. A2), and the difference between model simulations and observations (Eq. A3):

$$
\begin{aligned}
& J=J_{\text {prior }}+J_{\mathrm{obs}} \\
& J_{\text {prior }}=\sum_{i=1}^{m} \frac{1}{8}\left[\frac{1}{\left(\sigma_{i}^{1}\right)^{2}}\left(\left|p_{i}-p_{i}^{1}\right|-\left(p_{i}-p_{i}^{1}\right)\right)^{2}\right. \\
& \left.+\frac{1}{\left(\sigma_{i}^{\mathrm{u}}\right)^{2}}\left(\left|p_{i}-p_{i}^{\mathrm{u}}\right|+\left(p_{i}-p_{i}^{\mathrm{u}}\right)\right)^{2}\right] \\
& J_{\mathrm{obs}}=\frac{1}{2}\left(f\left(p_{i}\right)-y\right)^{T} R^{-1}\left(f\left(p_{i}\right)-y\right) .
\end{aligned}
$$

$J_{\text {prior }}$ constrains the updated parameters within their prior empirical ranges (Table 2) so that they are physically reasonable (Schartau et al., 1999). $p_{i}^{1}$ and $p_{i}^{\mathrm{u}}$ are upper and lower limits of parameter $p_{i}$. A parameter that is smaller than its lower limit or larger than its upper limit follows a normal distribution with standard deviation of $\sigma_{i}^{1}$ or $\sigma_{i}^{\mathrm{u}}$, respectively. $J_{\text {obs }}$ penalizes the updated parameters if model outputs $\left(\boldsymbol{f}\left(\boldsymbol{p}_{i}\right)\right)$ are deviated from observations $(\boldsymbol{y})$. $\mathbf{R}$ is the error covariance of observations.

The Adjoint-TEM is an adjoint version of the original TEM model (Errico 1997; Giering and Kaminski, 1998), which estimates the gradient of target variables (e.g., GPP) with respect to control variables (e.g., model parameters of interest) at each numerical step. By backward integration of these intermediate gradients $\left(\frac{\partial \boldsymbol{g}_{i}}{\partial \boldsymbol{g}_{i-1}}\right)$, the gradient of cost function with respect to model parameters $\left(\nabla_{p} J\right)$ could be calculated with Eq. (A4):

$$
\nabla_{\boldsymbol{p}} J=\left(\frac{\partial \boldsymbol{g}_{1}}{\partial \boldsymbol{p}}\right)^{\mathrm{T}} \cdot \ldots \cdot\left(\frac{\partial \boldsymbol{g}_{i}}{\partial \boldsymbol{g}_{i-1}}\right)^{\mathrm{T}} \cdot \ldots \cdot\left(\frac{\partial \boldsymbol{g}_{n}}{\partial \boldsymbol{g}_{n-1}}\right)^{\mathrm{T}} \cdot\left(\frac{\partial J}{\partial \boldsymbol{g}_{n}}\right)^{\mathrm{T}}
$$

where $\left(\frac{\partial \boldsymbol{g}_{i}}{\partial \boldsymbol{g}_{i-1}}\right)^{\mathrm{T}}$ is the transpose of Jacobian matrix. In the Jacobian matrix $\left(\frac{\partial \boldsymbol{g}_{i}}{\partial \boldsymbol{g}_{i-1}}\right), \boldsymbol{g}_{i}$ is a vector of output variables at $i$ th numerical step and $\boldsymbol{g}_{i-1}$ is a vector of input variables at $i-1$ th numerical step.

The gradient of cost function with respect to model parameters $\left(\nabla_{p} J\right)$ indicates the decreasing direction of the cost function. Therefore, the model parameters could be updated as

$p_{\text {new }}=p_{\text {old }}-a \cdot \nabla_{p} J$,

where $a$ is the step size. The new model parameters ( $\left.p_{\text {new }}\right)$ then could be used to update cost function (Eqs. A1-A3) and the gradient of cost function with respect to model parameters (Eq. A4). Iteratively, model parameters are optimized when the $\nabla_{p} J$ is smaller enough, or model outputs $\boldsymbol{f}(\boldsymbol{p})$ are close enough to observational data $\boldsymbol{y}$.

Acknowledgements. This research is supported with projects funded by NSF (DEB-0919331), the NSF Carbon and Water in the Earth Program (NSF-0630319), the NASA Land Use and Land Cover Change program (NASA-NNX09AI26G), Department of Energy (DE-FG02-08ER64599), the NSF Division of Information \& Intelligent Systems (NSF-1028291), and DOE/Lawrence Berkeley National Laboratory IMPACTS Program. This research was also in part supported by the Director, Office of Science, Office of Biological and Environmental Research of the US Department of Energy under contract no. DE-AC02-05CH11231 as part of their Earth System Modeling Program. We thank AmeriFlux network for providing site-level flux data for model parameterization and verification.

Edited by: X. Wang 


\section{References}

Barber, S. A. and Cushman, J. H.: Nitrogen uptake model for agronomic crops, in: Modeling wastewater renovation-land treatment, edited by: Iskandar, I. K., Wiley-interscience, New York, New York, USA, 383-409, 1981.

Bennett, J. N. and Prescott, C. E.: Organic and inorganic nitrogen nutrition of western red cedar, western hemlock and salal in mineral N-limited cedar-hemlock forests, Oecologia, 141, 468-476, 2004.

Berendse, F. and Aerts, R.: Nitrogen-use-efficiency: a biologically meaningful definition?, Funct. Ecol., 1, 293-296, 1987.

Black, C.: Soil fertility evaluation and control, CRC Press, Boca Raton, Florida, USA, Chaper 4-4.3, 1993.

Chapin, F. S., Van Cleve, K., and Chapin, M. C.: Soil temperature and nutrient cycling in the tussock growth form of Eriophorum vaginatum, J. Ecol., 67, 169-189, 1979.

Chapin, F. S., Fetcher, N., Kielland, K., Everett, K. R., and Linkins, A. E.: Productivity and nutrient cycling of Alaskan tundra: enhancement by flowing soil water, Ecology, 69, 693-702, 1988.

Chapin, F. S., Moilanen, L., and Kielland, K.: Preferential use of organic nitrogen for growth by a non-mycorrhizal arctic sedge, Nature, 361, 150-153, 1993.

Conway, T. J., Tans, P. P., Waterman, L. S., Thoning, K. W., Kitzis, D., Masarie, K. A., and Zhang, N.: Evidence for interannual variability of the carbon cycle from the National Oceanic and Atmospheric Administration/Climate Monitoring and Diagnostics Laboratory Global Air Sampling Network, J. Geophys. Res.Atmos., 99, 22831-22855, 1994.

Dyck, W. J., Mees, C. A., and Hodgkiss, P. D.: Nitrogen availability and comparison to uptake in two New Zealand pinus radiate forests, New Zeal. J. For. Sci., 17, 338-352, 1987.

Errico, R. M.: What is an adjoint model?, B. Am. Meteorol. Soc., 78, 2577-2591, 1997.

Giering, R. and Kaminski, T.: Recipes for adjoint code construction, ACM T. Math. Software, 24, 437-474, 1998.

Harmsen, G. W. and Van Schreven, D. A.: Mineralization of organic nitrogen in soil, in: Advances in agronomy, edited by: Norman, A., Academic Press, New York, USA, 300-382, 1955.

Heimann, M., Esser, G., Haxeltine, A., Kaduk, J., Kicklighter, D. W., Knorr, W., Kohlmaier, G. H., McGuire, A. D., Melillo, J., and Moore, B.: Evaluation of terrestrial carbon cycle models through simulations of seasonal cycle of atmospheric $\mathrm{CO}_{2}$ : First results of a model intercomparison study, Global Biogeochem. Cy., 12, 1-24, doi:10.1029/97GB01936, 1998.

Hobbie, J. E. and Hobbie, E. A.: ${ }^{15} \mathrm{~N}$ in symbiotic fungi and plants estimates nitrogen and carbon fluxes rates in arctic tundra, Ecology, 87, 816-822, 2006.

Hodge, A., Robinson, D., and Fitter, A.: Are microorganisms more effective than plants at competing for nitrogen?, Trends Plant Sci., 5, 304-308, 2000a.

Hodge, A., Stewart, J., Robinson, D., Griffiths, B. S., and Fitter, A. H.: Competition between roots and soil micro-organisms for nutrients from nitrogen-rich patches of varying complexit, J. Ecol., 88, 150-164, 2000b.

Itoh, S. and Barber, S. A.: Phosphorus uptake by six plant species as related to root hairs, Agron. J., 75, 457-461, 1983.

Jones, D. L., and Darrah, P. R.: Amino-acid influx at the soil-root interface of Zea mays L. and its implications in the rhizosphere, Plant Soil, 163, 1-12, 1994.
Jones, D. L., Healey, J. R., Willett, V. B., Farrar, J. F., and Hodge, A.: Dissolved organic nitrogen uptake by plants - an important N uptake pathway?, Soil Biol. Biochem., 37, 413-423, 2005.

Kalnay, E., Kanamitsu, M., Kistler, R., Collins, W., Deaven, D., Gandin, L., Iredell, M., Saha, S., White, G., and Woollen, J.: The NCEP/NCAR 40-Year Reanalysis Project, B. Am. Meteorol. Soc., 77, 437-471, 1996.

Kielland, K.: Amino acid absorption by arctic plants: implications for plant nutrition and nitrogen cycling, Ecology, 75, 2373-2383, 1994.

Kielland, K., McFarland, J. M., Ruess, R. W., and Olson, K.: Rapid Cycling of Organic Nitrogen in Taiga Forest Ecosystems, Ecosystems, 10, 360-368, 2007.

Leadley, P. W., Reynolds, J. F., and Chapin, F. S.: A model of Nitrogen uptake by Eriophorum Vaginatum roots in the field: ecological implications, Ecol. Monogr., 67, 1-22, 1997.

Lin, B. L., Sakoda, A., Shibasaki, R., Goto, N., and Suzuki, M.: Modelling a global biogeochemical nitrogen cycle in terrestrial ecosystems, Ecol. Model., 135, 89-110, 2000.

Lipson, A. D. and Monson, K. R.: Plant-microbe competition for soil amino acids in the alpine tundra: effects of freeze-thaw and dry-rewet events, Oecologia, 113, 406-414, 1998.

Lipson, A. D. and Nasholm, T.: The unexpected versatility of plants: organic nitrogen use and availability in terrestrial ecosystems, Oecologia, 128, 305-316, 2001.

Lipson, A. D., Raab, K. T., Schmidt, K. S., and Monson, K. R.: Variation in competitive abilities of plants and microbes for specific amino acids, Biol. Fertil. Soils, 29, 257-261, 1999.

Lipson, A. D., Raab, K. T., Schmidt, K. S., and Monson, K. R.: An empirical model of amino acid transformations in an alpine soil, Soil Biol. Biochem., 33, 189-198, 2001.

Loveland, T. R. and Belward, A. S.: The IGBP-DIS global 1-km land cover data set, DIScover: first results, Int. J. Remote Sens., 65, 1021-1031, 1997.

Masarie, A. K. and Tans, P. P.: Extension and integration of atmospheric carbon dioxide data into a globally consistent measurement Record, J. Geophys. Res.-Atmos., 100, 11593-11610, 1995.

McGuire, A. D., Melillo, J. M., Joyce, L. A., Kicklighter, D. W., Grace, A. L., Moore, B., and Vorosmarty, C. J.: Interactions between carbon and nitrogen dynamics in estimating net primary productivity for potential vegetation in North America, Global Biogeochem. Cy., 6, 101-124, 1992.

Melillo, J. M., McGuire, A. D., Kicklighter, D. W., Moore, B., Vorosmarty, C. J., and Schloss, A. L.: Global climate change and terrestrial net primary production, Nature, 63, 234-240, 1993.

Nasholm, T., Ekblad, A., Nordin, A., Giesler, R., Hogberg, M., and Hogberg, P.: Boreal forest plants take up organic nitrogen, Nature, 392, 914-916, 1998.

Nasholm, T., Kielland, K., and Ganeteg, U.: Uptake of organic nitrogen by plants, New Phytol., 182, 31-48, 2009.

Norby, R. J., Warren, J. M., Iversen, C. M., Medlyn, B. E., and McMurtrie, R. E.: $\mathrm{CO}_{2}$ enhancement of forest productivity constrained by limited nitrogen availability, P. Natl. A. Sci. USA, 107, 19368-19373, 2010.

Ohlund, J., and Nasholm, T.: Growth of conifer seedlings on organic and inorganic nitrogen sources, Tree Physiol., 21, 1319-1326, 2001. 
Pappas, C., Fatichi, S., Leuzinger, S., Wolf, A., and Burlando, P.: Sensitivity analysis of a process-based ecosystem model: Pinpointing parameterization and structural issues, J. Geophys. Res.-Biogeo., 118, 505-528, 2013.

Parton, W., Scurlock, J., Ojima, D., Gilmanov, T., Scholes, R., Schimel, D., Kirchner, T., Menaut, J. C., Seastedt, T., and Garcia Moya, E.: Observations and modeling of biomass and soil organic matter dynamics for the grassland biome worldwide, Global Biogeochem. Cy., 7, 785-809, 1993.

Persson, J., Hogberg, P., Ekblad, A., Hogberg, M. N., Nordgren, A., and Nasholm, T.: Nitrogen acquisition from inorganic and organic sources by boreal forest plants in the field, Oecologia, 137, 252-257, 2003.

Potter, C. S., Randerson, J. T., Field, C. B., Matson, P. A., Vitousek, P. M., Mooney, H. A., and Klooster, S. A.: Terrestrial ecosystem production: a process model based on global satellite and surface data, Global Biogeochem. Cy., 7, 811-841, 1993.

Raab, T. K., Lipson, D. A., and Monson, R. K.: Soil amino acid utilization among species of the Cyperaceae: plant and soil processes, Ecology, 80, 2408-2419, 1999.

Raich, J. W., Rastetter, E. B., Melillo, J. M., Kicklighter, D. W., Steudler, P. A., Peterson, B. J., Grace, B., Moore, A. L., and Vorosmarty, C. J.: Potential net primary productivity in South America: application of a global model, Ecol. Appl., 1, 399-429, 1991.

Reich, P. B., Hobbie, S. E., Lee, T., Ellsworth, D. S., West, J. B., Tilman, D., Knops, J. M., Naeem, S., and Trost, J.: Nitrogen limitation constrains sustainability of ecosystem response to $\mathrm{CO}_{2}$, Nature, 440, 922-925, 2006a.

Reich, P. B., Hungate, B. A., and Luo, Y.: Carbon-nitrogen interactions in terrestrial ecosystems in response to rising atmospheric carbon dioxide, Annu. Rev. Ecol. Evol. S., 37, 611-636, 2006b.

Running, S. W. and Coughlan, J. C.: A general model of forest ecosystem processes for regional applications I. Hydrologic balance, canopy gas exchange and primary production processes, Ecol. Model., 42, 125-154, 1988.

Running, S. W. and Gower, S. T.: FOREST-BGC, a general model of forest ecosystem processes for regional applications. II. Dynamic carbon allocation and nitrogen budgets, Tree Physiol., 9, 147-160, 1991.

Schartau, M., Oschlies, A., and Willebrand, J.: Parameter estimates of a zero-dimensional ecosystem model applying the adjoint method, Deep-Sea Res. Pt. II., 48, 1769-1800, 1999.

Schimel, J. P. and Bennett, J.: Nitrogen mineralization: challenges of a changing paradigm, Ecology, 85, 591-602, 2004.
Schimel, J. P. and Chapin, F. S.: Tundra plant uptake of amino acid and $\mathrm{NH}_{4}^{+}$nitrogen in situ: plants compete well for amino acid $\mathrm{N}$, Ecology, 77, 2142-2147, 1996.

Smith, S. and Read, D.: Mycorrhizal symbiosis, Second edition, Academic Press, San Diego, California, USA, 1997.

Sokolov, A. P., Kicklighter, D. W., Melillo, J. M., Felzer, B. S., Schlosser, C. A., and Cronin, T. W.: Consequences of considering carbon-nitrogen interactions on the feedbacks between climate and the terrestrial carbon cycle, J. Climate, 21, 3776-3796, 2008.

Tateno, M. and Chapin, F. S.: The logic of carbon and nitrogen interactions in terrestrial ecosystems, Am. Nat., 149, 723-744, 1997.

Thornton, B. and Robinson, D.: Uptake and assimilation of nitrogen from solutions containing multiple N sources, Plant Cell Environ., 28, 813-821, 2005.

Tinker, P. B. and Nye, P. H.: Solute movement in the rhizosphere, Oxford University Press, 2000.

Zaehle, S., Sitch, S., Smith, B., and Hatterman, F.: Effects of parameter uncertainties on the modeling of terrestrial biosphere dynamics, Global Biogeochem. Cy., 19, GB3020, doi:10.1029/2004GB002395, 2005.

Zhu, Q. and Zhuang, Q.: Improving the quantification of terrestrial ecosystem carbon dynamics over the United States using an adjoint method, Ecosphere-data assimilation special feature, 4, 118, doi:10.1890/ES13-00058.1, 2013.

Zhuang, Q., Romanovsky, V. E., and McGuire, A. D.: Incorporation of a permafrost model into a large-scale ecosystem model: Evaluation of temporal and spatial scaling issues in simulating soil thermal dynamics, J. Geophys. Res.-Atmos., 106, 33649-33670, 2001.

Zhuang, Q., McGuire, A. D., O’Neil, K. P., Harden, J., Romanovsky, V. E., and Yarie, J.: Modeling the soil thermal and carbon dynamics of a fire chronosequence in interior Alaska, J. Geophys. Res.-Atmos., 107, 8147, doi:10.1029/2001JD001244, 2002.

Zhuang, Q., McGuire, A. D., Melillo, J. M., Clein, J. S., Dargaville, R. J., Kicklighter, D. W., Myneni, R. B., Dong, J., Romanovsky, V. E., Harden, J., and Hobbie, J. E.: Carbon cycling in extratropical terrestrial ecosystems of the Northern Hemisphere during the 20th century: A modeling analysis of the influences of soil thermal dynamics, Tellus B, 55, 751-776, 2003.

Zhuang, Q., He, H., Lu, Y., Ji, L., Xiao, J., and Luo, T.: Carbon dynamics of terrestrial ecosystems on the Tibetan Plateau during the 20th century: an analysis with a process-based biogeochemical model, Global Ecol. Biogeogr., 19, 649-662, 2010. 